\title{
Molecular structure of imidazoline inhibitor and quantum chemical analysis of corrosion inhibition performance of $\mathrm{Zn}$ atom
}

\author{
Min Chen ${ }^{1,2}$, Yushan Cheng ${ }^{1,2}$, Huiwu Xu ${ }^{1,2}$,Jinying Wu ${ }^{1,2}$, Mian Xue ${ }^{1,2, *}$, Xiaoguang Zhang ${ }^{1,2}$ \\ ${ }^{1}$ Henan Academy of Sciences \\ ${ }^{2}$ Henan Academy of Sciences Energy Research Institute Co. , Ltd. \\ Henan zhengzhou 450008
}

\begin{abstract}
The adsorption potential energy curves of imidazoline compounds and $\mathrm{Zn}$ atom were calculated by quantum chemistry method.The adsorption energy, imidazoline ring, the coordination bond length between nitrogen atom and $\mathrm{Zn}$ atom, the double atom interaction energy and the overlapping population number were obtained.The results show that the introduction of power-providing groups or substituted aromatics into imidazoline ring can enhance the chemical adsorption force between $\mathrm{N}$ and $\mathrm{Zn}$. The calculation results can provide a useful theoretical basis for the design of corrosion inhibitors with better performance.
\end{abstract}

\section{Introduction}

Imidazoline type corrosion inhibitor is a kind of adsorption type corrosion inhibitor with good anticorrosion effect. There are many imidazoline derivatives because of different raw materials and different substituents on imidazoline ring.There are many reports on the experimental studies of these compounds.[1-6]Relatively speaking, there are few reports about the theoretical research, but there is no report about the relationship between molecular structure and corrosion inhibition performance by quantum chemistry method.The chemical adsorption energy of imidazoline series, series compounds and $\mathrm{Zn}$ atom has been calculated by quantum chemistry method, and the relationship between the adsorption energy and the corrosion inhibition property has been discussed.

\section{Computational models and methods}

According to the theory of chemisorption, the corrosion inhibitor molecules adsorbed chemically with the metal and formed a dense oil film on the surface of the metal. (Fig.1) Macroscopically, the oil film is composed of a single inhibitor molecule arranged on the metal surface.From the microscopic molecular level and electronic structure, the process of chemical adsorption between single molecule and metal surface is essentially the interaction between lone pair electrons of nitrogen atom in molecule and d-orbital of $\mathrm{Zn}$ atom to form coordination bond.Therefore, the chemical adsorption energy and the strength of the coordination bond can be calculated by the quantum chemistry method, and the corrosion inhibition performance can be predicted.Therefore, imidazoline compounds I, II, III, IV, $\mathrm{V}$ and VI were calculated and studied. Fig. 2 shows the adsorption model of imidazoline compounds with $\mathrm{Zn}$.The structure of compound $\mathrm{I}$ is shown in Fig. 3. In the structure of imidazoline compounds shown in figures 2 and $3, \mathrm{R}_{4}$ is the $\mathrm{CH} 2 \mathrm{C} \mathrm{H} 2 \mathrm{CH} 2 \mathrm{CH} 3$ group.Compounds II, III, IV, V and VI are represented when the $\mathrm{R}$ in the structure of imidazolium and morpholine compounds in Fig. 2.are $\mathrm{H}, \mathrm{CH}\left(\mathrm{CH}_{3}\right)_{3}, \mathrm{CH}=\mathrm{CH}_{2}, \mathrm{Ph}-\mathrm{R}_{4}$ and $\mathrm{Ph}-\mathrm{NO}_{2}$ groups, respectively.

In this paper, the complete optimization of the above compounds is calculated by B3LYP method, $\mathrm{Zn}$ atom is added to the optimized equilibrium geometry, and $\mathrm{Zn}$ atom is connected to $\mathrm{N}$ atom of imidazoline ring, the distance between $\mathrm{N}$ and $\mathrm{Zn}$ atom $\mathrm{RN} \mathrm{Zn}$ is defined as the chemical adsorption reaction coordinate, I. E. Model II. The CNDO / $2 \mathrm{M}$ method is used to decrease $\mathrm{R}_{\mathrm{N}} \mathrm{Zn}$ in order to simulate and calculate the potential energy curve of chemical adsorption. 


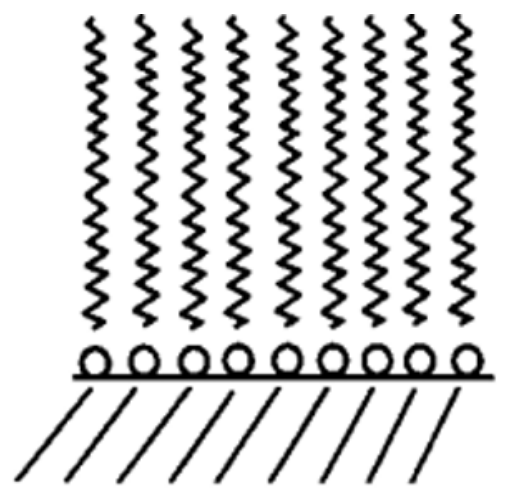

Fig. 1 Model of chemical adsorption

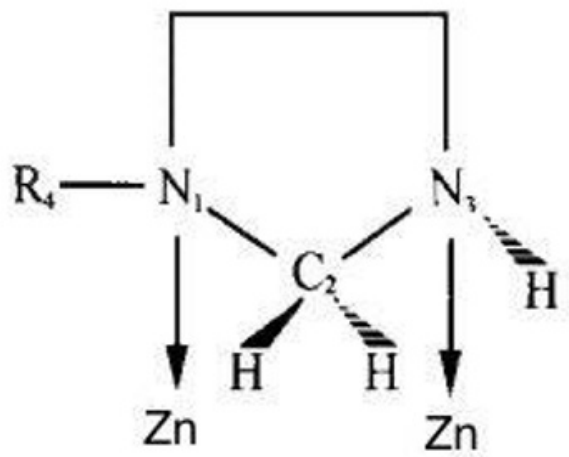

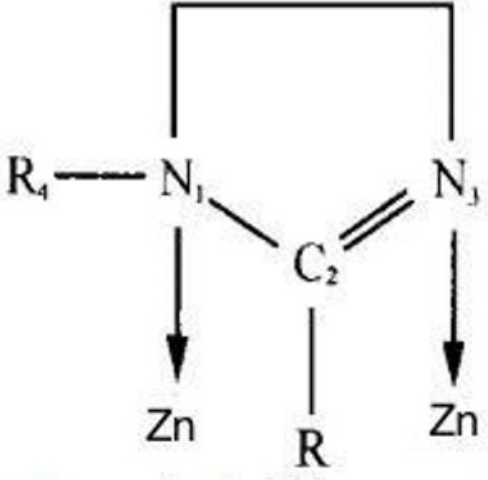

Fig. 2 Adsorption model of imidazoline and $\mathrm{Zn}$ atom

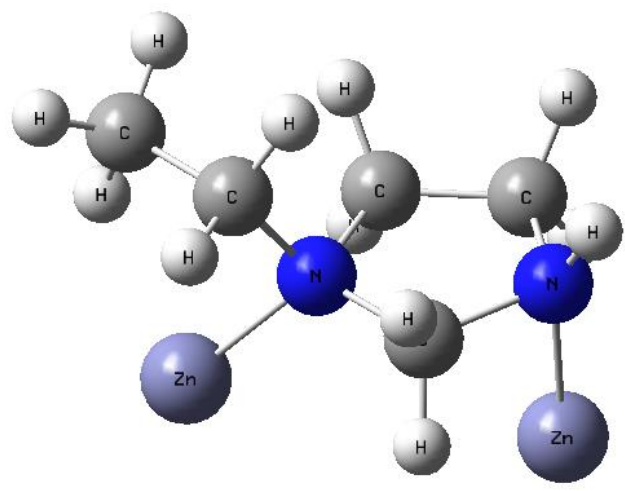

Fig. 3 Structure of compoundI The results

The equilibrium geometry, net charge (QA) distribution and frontier molecular orbital(HOMO) coefficient of these compounds have been obtained by full optimization calculations using the B3LYP method. Some results are shown in Table 1. The chemical adsorption and adsorption potential energy curves of compounds I $\sim \mathrm{VI}$ and $\mathrm{Zn}$ were obtained by point-by-point optimization calculation of CNDO /
2M.(Fig.4) The adsorption energy(EADS) is obtained from the energy difference between the final state and the initial state. The distance between the adsorbed terminal state $\mathrm{N}$ and the $\mathrm{Zn}$ atom, the coordination bond length, the diatomic interaction energy ( $\mathrm{EN} \mathrm{Zn}$ ) and the overlapping population (QN Zn), are calculated and listed in Table 2.

Table 1 Net charge and the coefficient of HOMO contributed by N1 and N3 atoms

\begin{tabular}{|c|c|c|c|c|c|c|c|c|}
\hline \multirow{2}{*}{ Compound } & \multicolumn{3}{|c|}{ Coefficient of $\mathrm{N}_{1}$ atom } & \multicolumn{3}{|c|}{ Coefficient of $\mathrm{N}_{3}$ atom } & \multicolumn{2}{|c|}{$\mathrm{Q}_{\mathrm{N}}($ Net Charge $) / \mathrm{e}$} \\
\hline & $P_{x}$ & $P_{Y}$ & $\mathrm{P}_{\mathrm{Z}}$ & $\mathrm{P}_{\mathrm{X}}$ & $\mathrm{P}_{\mathrm{Y}}$ & $\mathrm{P}_{\mathrm{Z}}$ & $\mathrm{Q}_{\mathrm{N} 1}$ & $\mathrm{Q}_{\mathrm{N} 3}$ \\
\hline I & -0.1130 & 0.2141 & 0.6744 & 0.0488 & -0.0057 & 0.2333 & -0.4555 & -0.3266 \\
\hline II & -0.0506 & 0.0956 & 0.6476 & 0.1174 & -0.0989 & -0.5068 & -0.4547 & -0.3143 \\
\hline III & -0.0542 & 0.0953 & 0.6403 & 0.1352 & -0.0989 & -0.5097 & -0.4439 & -0.3096 \\
\hline IV & -0.0401 & 0.0719 & 0.6378 & 0.1098 & -0.0812 & -0.5261 & -0.4461 & -0.3072 \\
\hline VI & -0.0566 & 0.1054 & 0.6391 & 0.1214 & -0.1062 & -0.4949 & -0.4370 & -0.2918 \\
\hline
\end{tabular}

Table 2 Chemical Adsorption f or compoundsI $\sim$ VI and Zn atom

\begin{tabular}{|c|c|c|c|c|c|c|c|}
\hline \multirow{2}{*}{ Compound } & \multirow{2}{*}{$\mathrm{R}_{\mathrm{NZn}}(\mathrm{TS}) / \mathrm{nm}$} & \multirow{2}{*}{$\mathrm{R}_{\mathrm{NZn}}(\mathrm{FS}) / \mathrm{nm}$} & \multicolumn{2}{|c|}{$\mathrm{E}_{\mathrm{NZn}}(\mathrm{FS}) / \mathrm{au}$} & \multicolumn{2}{|c|}{$\mathrm{Q}_{\mathrm{NZn}}(\mathrm{FS}) / \mathrm{e}$} & \multirow{2}{*}{ Eabs/au } \\
\hline & & & $\mathrm{N}_{1}-\mathrm{Zn}$ & $\mathrm{N}_{3}-\mathrm{Zn}$ & $\mathrm{N}_{1}-\mathrm{Zn}$ & $\mathrm{N}_{3}-\mathrm{Zn}$ & \\
\hline
\end{tabular}




\begin{tabular}{|l|l|l|l|l|l|l|l|}
\hline I & 0.420 & 0.204 & -0.4605 & -0.3394 & 0.3751 & 0.3102 & -0.2332 \\
\hline II & 0.375 & 0.182 & -0.5049 & -0.5661 & 0.5201 & 0.5616 & -0.3203 \\
\hline III & 0.350 & 0.180 & -0.5239 & -0.5917 & 0.5307 & 0.5917 & -0.3687 \\
\hline IV & 0.418 & 0.182 & -0.4685 & -0.6201 & 0.5011 & 0.5810 & -0.5057 \\
\hline V & 0.330 & 0.180 & -0.5491 & -0.7074 & 0.5424 & 0.6226 & -0.5644 \\
\hline VI & 0.360 & 0.180 & -0.4767 & -0.5405 & 0.5105 & 0.5396 & -0.1317 \\
\hline
\end{tabular}

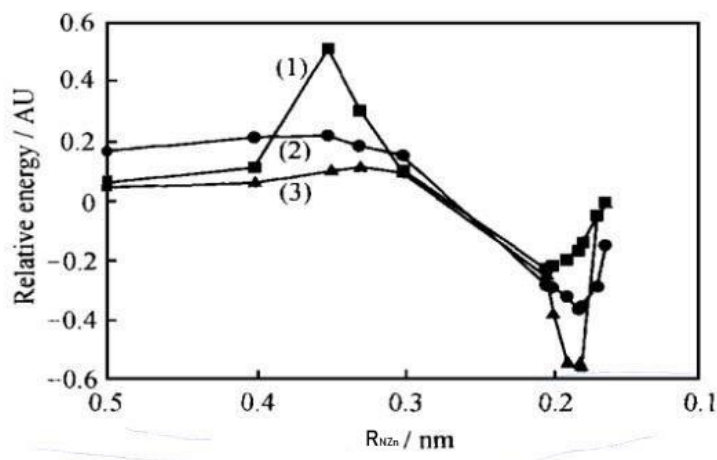

Fig. 4 The potential curves of the chemical adsorption of compounds I , III , V and Fe atoms Energies are relative to adduct at $\mathrm{R}_{\mathrm{NZn}}=$ 6. 0, absolute energies are - 100. 7166, - 125. 4635 and - 144. 7762( AU)for compoundsI ,III and V

\section{Discuss}

\subsection{Molecular structure of ground state}

\section{1. 1.Charge distribution and HOMO}

By calculating the net charge distribution of these compounds, it is found that the negative charges of $\mathrm{N} 1$ and $\mathrm{N} 3$ atoms in the molecules are $-0.4555 \sim-0.4370 \mathrm{e}$ and $-0.3266 \sim-0.2918 \mathrm{e}$. The $\mathrm{N}$ Atom in the imidazoline ring is the main contribution to the coefficient of the highest occupied molecular orbital(HOMO), as shown in Table 1.For example, the coefficient of the N1 atom $\mathrm{pZ}$ is $0.6744 \sim 0.6391$ range. The results show that the chemical adsorption of imidazoline corrosion inhibitor is produced by the interaction of $\mathrm{N}$ atom and $\mathrm{Zn}$ atom.

\subsubsection{Conjugated properties of imidazoline ring}

The results show that the inhibition performance of imidazoline is mainly related to the presence or absence of ring.Therefore, the structural properties of the ring are investigated. It is found that the structure of imidazoline ring is almost PLANAR, but not a complete planar ring. The $\mathrm{C} 2$ and N3 atoms deviate from the plane by about 15 degrees.In compound I, the two $\mathrm{C}-\mathrm{N}$ bonds on the ring are 0.1461 and $0.1462 \mathrm{~nm}$, a standard single bond is $0.1460 \mathrm{~nm}$. The non-existence of the $\mathrm{p}-\pi$ conjugation phenomenon of $\mathrm{n}$ is shown in Fig. 5a. In Compound II
VI, C2 =N3 is a double bond, the lone on N1 atom, the pair of electrons can be $\mathrm{p}-\pi$ conjugated with $\mathrm{C} 2=\mathrm{N} 3$, and $\mathrm{N} 1-\mathrm{C} 2-\mathrm{N} 3$ chain can be $\mathrm{p}--\pi$ conjugated, as shown in Fig. 5 b.

Because of the conjugation, the two $\mathrm{C}-\mathrm{N}$ after optimization are

0.1421 and $0.1301 \mathrm{~nm}$, shorter than the standard single bond $0.146 \mathrm{~nm}$, and longer than the standard double bond $0.128 \mathrm{~nm}$. Due to the delocalization property of the $\mathrm{P}--\pi$ conjugated system, the electrons can be easily transferred and chemically adsorbed on $\mathrm{Zn}$ atoms to form a valence bond.Therefore, it can be inferred that the adsorption force of imidazoline compounds with $p-\pi$ conjugate system to $\mathrm{Zn}$ atoms will be stronger than that of compounds without P- $\pi$ conjugate system. Moreover, with the enhancement of electron donor or conjugation properties, the chemical adsorption force increases.<smiles>[R][C@H]1C2CN3CN([C@@H]13)N2[R]</smiles>

(a)

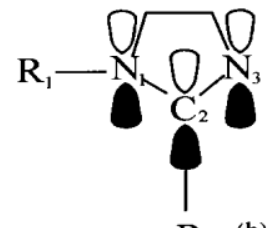

$\mathrm{R}_{2}$ (b)
Fig. 5 Conjugated system of compoundI $\sim$ VI

(a) Non-con jugated system of compound I ;

(b) $\mathrm{p}-\pi$ Conjugat ed System of Compound sII $\sim$ VI

\subsection{Adsorption potential energy curve}




\subsubsection{Variation trend of adsorption potential energy curve}

In order to investigate the influence of substituents on the chemical adsorption force, the adsorption potential energy curves of $\mathrm{Zn}$ atoms and 6 different substituents were calculated by B3LYP method.RN $\mathrm{Zn}=0.60 \mathrm{~nm}$ is used as the initial state to calculate the potential energy curve for relative comparison.According to the calculated adsorption potential energy curve (see the representative curve in Fig. 4), as distance RNZn decreases, energy increases, and the adsorption transition state (TS) is formed at about $0.36 \mathrm{~nm}$ of RNZn, and then the energy starts to decline. When RNZn is about $0.182 \mathrm{~nm}$, the energy reaches a local minimum, forming the adsorption final state (FS).If you go down RN Zn, it's going to go up again. It shows that the imidazoline compound must pass a small energy barrier in the process of chemical adsorption with $\mathrm{Zn}$ atom, and finally reach a stable adsorption final state. It is also found that the chemisorption barrier varies with the substituents (see Fig. 4 for details).No p - PI conjugate system of compound I has the highest energy barrier, with p - PI conjugated system and alkyl stupid compounds can II $\mathrm{V}$ base is very small, almost as a spontaneous process.

\subsection{Bond lengths of adsorbed transition states}

Careful analysis of the RN Zn distance between TS and FS also reveals interesting problems. It can be seen from Table 2 that the distance between the 6 compounds and $\mathrm{Zn}$ atom adsorption transition state $\mathrm{RN} \mathrm{Zn}$ varies.Among them, compounds I and VI in RN Zn respectively 0.42 and $0.36 \mathrm{~nm}$ to reach adsorption transition state, and have higher adsorption energy barrier, reflect the two compounds are difficult to form chemical adsorption with $\mathrm{Zn}$ atoms transition state.Compound II $\sim \mathrm{V}$ in $\mathrm{RN}$ $\mathrm{Zn}$ for $0.37 \mathrm{~nm}$ to reach adsorption transition state, adsorption energy barrier is low. From the kinetic point of view, the electron donor group or alkyl aromatics is favorable for chemisorption.

\subsection{Bond length and adsorption energy of the final adsorption state}

When arrived at the end of the adsorption state, compound I RN Zn as $0.204 \mathrm{~nm}$, compound II and IV RN $\mathrm{Zn}$ is $0.182 \mathrm{~nm}$, the rest are $0.180 \mathrm{~nm}$. For compound I $\mathrm{V}$, as RNZn is reduced, the absolute value of the corresponding EN Zn and QN Zn generally showed a trend of increase (see chart 2). This not only shows that the coordination bond between compound I VI and Zn is formed, but also has strong chemical adsorption energy.In particular, compounds II VI with $\mathrm{P}-\pi$ conjugated system have a coordination bond length of $0.182 \mathrm{~nm}$, the ratio of $\mathrm{N}$ to $\mathrm{Zn}$ atomic radius is $0.201 \mathrm{~nm}$ shorter.The results show that the chemical adsorption force between $\mathrm{N}$ and $\mathrm{Zn}$ is very strong, and the chemical and adsorption force increases with the increase of electron donor or conjugation of substituents. This force can get quantitative (EADS) from the chemical adsorption, namely no p - PI conjugate system of compound I EADS to a minimum, with $\mathrm{p}$ - PI conjugate system of compound II $\sim \mathrm{V}$ adsorption can be larger, and from the compound I $\sim \mathrm{V}$, EADS, in turn, increases.A set of parameters RN Zn, EN Zn and QN Zn, which describe the strength of the interaction between $\mathrm{N} 3$ and $\mathrm{Zn}$, show that the chemical adsorption force increases in turn, as shown in table 2, but the absolute value of EN $\mathrm{Zn}$ and QN Zn of compound VI decrease, this is explained below.

\subsection{Effect of substituent on adsorption energy}

These changes can be explained by the molecular structure of the compounds and the substituent effect.In compound I, due to the absence of $\mathrm{p}--\pi$ system and $\pi$ delocalized electrons, $\mathrm{C} 2$ atoms have no electron donor substituent group and only rely on the lone pair electrons of $\mathrm{N}$ atoms to interact with $\mathrm{Zn}$ atoms. Chemical adsorption force is weak and energy is high.Therefore, the length of the coordination bond is $0.204 \mathrm{~nm}$, and the EN Zn and QNZn are smaller. In Compound II VI, because of its $\mathrm{p}-\pi$ conjugation system, not only the lone pair electrons of $\mathrm{N}$ atoms interact with $\mathrm{Zn}$, but also the electrons of the conjugation system interact with $\mathrm{Zn}$ atoms more easily, forming coordination bonds and stable chemisorption states.For example, the substituent-free compound II RNZn on the C2 atom has $0.182 \mathrm{~nm}$, the EADS, ENZn and QNZn are smaller as shown in Table 2. RNZn with electron donor group or substituted aryl Group iii VI is 0.180nm, EADS, ENZn and QNZn were all larger and increased in turn.The effect of the substituents on the stability of the adsorbed state is shown from the thermodynamic point of view. For the compound VI, the electron cloud density of the conjugated system is reduced due to the nitro-electron absorption, which results in the reduction of the adsorption force between $\mathrm{N}$ and $\mathrm{Zn}$ atoms, and the smaller adsorption force between EADS, EN Zn and QN $\mathrm{Zn}$.

Because the corrosion inhibitor and the metal surface chemical adsorption film more firm, the corrosion inhibition effect is better. Therefore, it can be roughly inferred that the inhibition effects of the above compounds are in the following order: Compounds V> IV $>$ III $>$ II $>>$ I $>$ VI.

\section{Conclusion}

(1)In imidazoline molecules, the negative charges of N1 and N3 atoms are the largest, and the highest orbital HOMO coefficients are mainly contributed by $\mathrm{N}$ atoms in the imidazoline ring, the chemical adsorption of imidazoline corrosion inhibitor is mainly produced by the interaction of $\mathrm{N}$ atom and $\mathrm{Zn}$ atom.

(2)From the results of calculation, the inhibitive effect of the above compounds can be roughly estimated, and the order is as follows:

V $>$ IV $>$ III $>$ II $>>$ I $>$ VI

(3)Imidazoline ring exists in $\mathrm{P}-\pi$ conjugated system, the introduction of electron donor group or substitution 
of aromatic hydrocarbon on the ring can enhance the chemical adsorption force of imidazoline molecule and metal surface and the fastness of the adsorbed film, so as to enhance its corrosion inhibition performance.

Fund Project: Science and Technology Development Project of Henan Academy of Sciences (Project No. 200606050)

\section{References:}

1. ]Yang Xiaoping, Li Zidong, etc. . Development and application of corrosion and complex inhibitor CZ3-1 + CZ3-3 IN MOXI gas field. Oilfield Chemistry, 1998,151:132-136.

2. Cao Wei, Shang Ying Hong, and so on. DEVELOPMENT OF CORROSION INHIBITOR IN REFINERY J. Corrosion Science and protection technology, 1997,93:251-254.

3. Zhou Tong, Xu Jiaye, Zhang Qun Zheng. Corrosion inhibition of imidazoline compounds on a 3 steel in hydrochloric acid. Oilfield Chemistry, 1997,144:317-319.

4. Lee shu-an, Huang Chao.Synthesis of imidazoline phosphate amphoteric Surfactant. Fine Petrochemicals, 1996,5:13-16.

5. Zheng J S, Zhao J G. Control of corrosion by inhibitors in drilling muds containing high concentration of $\mathrm{H} 2 \mathrm{~S}[\mathrm{~J}]$. Corrosion, 1993, 49( 2): 170- 174.

6. Kim min-hye, Yang bing-fei,etc.. Development of CL-1 CORROSION INHIBITOR J. Oilfield Chemistry, 1994,11:50-54 